\title{
A SOCIOLOGIA DOS MERCADOS ${ }^{1}$
}

\author{
Neil Fligstein* \\ Luke Dauter**
}

\begin{abstract}
A sociologia dos mercados tem sido um dos campos mais vibrantes da sociologia nos últimos 25 anos. Há uma boa dose de concordância de que os mercados são estruturas sociais caracterizadas por relações sociais extensas entre firmas, trabalhadores, fornecedores, clientes e governos. No entanto, assim como em tantas literaturas sociológicas, os campos teóricos que se formaram com frequência parecem falar sem levar os demais em consideração. Nós demonstramos que parte das discordâncias entre os campos teóricos se deve a diferenças na linguagem conceitual, e outras discordâncias estão ligadas ao fato de que os campos teóricos ignoram os conceitos em outros campos, o que torna suas teorias menos completas. Nós terminamos discutindo controvérsias mais profundas na literatura que parecem abertas tanto a novas conceptualizações, quanto a pesquisa empírica adicional.
\end{abstract}

Palavras-chave: Campos. Redes. Instituições. Performatividade. Cultura. Política.

O how they cling and wrangle, some who claim For preacher and monk the honored name! For, quarreling, each to his view they cling Such folk see only one side of a thing ${ }^{2}$

\section{INTRODUÇÃO}

A sociologia dos mercados tem sido um dos campos mais vibrantes da sociologia nos últimos 25 anos. ${ }^{3}$ Começando com um respingar de artigos empíricos e teóricos, ela se tornou um rio. Uma das peças seminais no campo, o trabalho de Granovetter (1985) intitulado Economic action and

* Professor do Departamento de Sociologia e Diretor do Centro para Cultura, Organização e Política/Instituto de Pesquisa em Trabalho e Emprego, na Universidade da Califórnia.

Department of Sociology. University of California. Berkeley, California 94720. fligst@berkeley.edu

* Candidato ao doutorado em Sociologia na Universidade da Califórnia, Berkeley. luked@berkeley.edu

${ }^{1}$ Publicado, originalmente, na Annual Review of Sociology, 2007, p. 105-128. Traduzido e revisado por Cristiano Fonseca Monteiro.

${ }^{2}$ Do texto de Jain e origem budista, Udana 68-69, "Parábola dos homens cegos e do elefante"

${ }^{3}$ Gostaríamos de distinguir a sociologia dos mercados do projeto mais amplo da sociologia econômica (Fligstein 2002). Seguindo Polanyi (1957), a sociologia econômica é o estudo geral das condições de produção e reprodução da vida social. Tal estudo incluiria pesquisas sobre consumo, a família e as ligações entre Estados e o ambiente doméstico, a formação escolar e a vida econômica em termos mais amplos (Smelser; Swedberg, 2005). A sociologia dos mercados se refere mais especificamente ao estudo de um tipo de troca social, aquela dos mercados, e a estruturação daquele tipo de troca social, sob as condições que chamamos de capitalistas. Esse foco inclui o social structure: the problem of embeddednes foi citado mais de 2500 vezes desde sua publicação, tornando-o o artigo mais citado na Sociologia no período pós-guerra. ${ }^{4}$ Embora os sociólogos tenham feito progresso significativo em seus esforços para entender as origens, operações e dinâmicas dos mercados como estruturas sociais, as perspectivas que emergiram inicialmente tenderam a permane-

estudo das firmas, dos mercados de produtos e mercados de trabalho, assim como seus elos mais amplos com fornecedores, trabalhadores e Estados, assim como o papel das culturas locais (i. e., locais no sentido de pertencer a um mercado particular), dos sistemas de significados na medida em que eles influenciam o que se pode chamar de "produtos", além do papel da moralidade na geração de tipos particulares de mercados.

${ }^{4}$ Recentemente, Jacobs (2005) calculou os artigos mais citados na American Sociological Review no período pósguerra. $\mathrm{O}$ artigo com mais citações foi o de DiMaggio e Powell (1983) sobre o "Isomorfismo institucional”, com 1700 citações. O artigo de Granovetter apareceu no American Journal of Sociology e, até onde sabemos, ninguém criou uma lista similar para esse periódico. No entanto, com quase 2500 citações, é difícil de acreditar que muitos artigos tenham superado o de Granovetter. Deveria ser notado também que o artigo de DiMaggio e Powell influenciou enormemente a sociologia dos mercados. Argumentamos que esse artigo influenciou enormemente pelo menos uma vertente de pensamento na sociologia dos mercados (a teoria institucional). Se esses dois artigos forem tomados como parte da fundação do campo, certamente os dois artigos mais citados da era pós-guerra estão no coração da sociologia dos mercados. 
cer separadas e distintas no nível teórico. Assim como os monges e pastores que não conseguiram ver o elefante inteiro na famosa parábola de Buda, os estudiosos, com frequência, têm enfocado um aspecto social particular dos mercados e agido como se isso fosse um entendimento mais geral.

Essa separação teórica produz dois problemas. Primeiro, porque muitos pesquisadores usam conceitos similares, mas os identificam por termos diferentes, gerando confusão sobre o grau em que se está dizendo coisas diferentes. Por exemplo, a maioria dos estudiosos, independentemente de sua abordagem, acredita que a cultura (significados partilhados, entendimentos normativos, identidades, práticas locais) desempenha um papel importante na construção dos mercados. Uma boa parte dessa sobreposição conceitual está escondida pelo uso de jargões (por exemplo, o uso de termos como quadros de referência, lógicas, performatividade, scripts, concepções de controle, ou conhecimento local). Assim, os estudiosos que alegam abordar seus problemas de pesquisa de uma perspectiva particular, na verdade, compartilham conceitos com uma vasta gama de outros estudiosos.

Em segundo lugar, na medida em que os estudiosos estão realmente dizendo coisas diferentes, é difícil avaliar o quanto suas perspectivas teóricas são complementares ou contraditórias. Quando um ponto de vista complementa outro, a teoria avança. Levar em consideração outros elementos possíveis na estruturação social dos mercados conduz a uma visão mais completa dos processos de mercado. No entanto, quando teorias se contradizem, os estudiosos precisam entender por que suas teorias se diferenciam e como essas diferenças podem ser exploradas de forma útil para avançar tanto a teoria como a pesquisa. O objetivo principal desta revisão é começar a desembaraçar o trabalho teórico e empírico dedicado à sociologia dos mercados, esclarecendo o que sabemos e onde os estudiosos realmente estão em desacordo.

A literatura (e a maneira como são oferecidos os cursos de pós-graduação) tem com frequência sido dividida em três grupos de teorias (Foucaude-Gourinchas, 2007), conforme os estudiosos usam (a) redes (Burt, 1992; Granovetter, 1974, 2005; White, 1981, 2002), (b) instituições (Dobbin, 1994; Fligstein, 1990, 2002; Powell; DiMaggio, 1991), ou (c) performatividade (Benuza; Stark, 2004; Callon, 1998; Callon; Munieza, 2005; Mackenzie; Milo, 2003; Mackenzie 2005) como mecanismos explicativos da emergência e dinâmica dos mercados. Os estudiosos na tradição das redes têm enfocado os laços tradicionais entre atores como a base material da estrutura social. Os institucionalistas têm enfocado o modo como a cognição e ação estão contextualizadas em regras de mercado, poder e normas. A escola de pensamento da performatividade vê a ação econômica como resultante de processos de cálculos que envolvem tecnologias e artefatos específicos que os atores empregam.

Essa divisão do campo exagera o quanto essas perspectivas são, de fato, grupos teóricos distintos. Todas as três abordagens se baseiam em uma visão dos mercados como arenas sociais onde firmas, seus fornecedores, clientes, trabalhadores e o governo interagem, assim como todas as três abordagens enfatizam o quanto as conexões desses atores afetam seu comportamento. A análise de rede é uma técnica para achar estruturas sociais em dados relacionais. Não é uma teoria das relações subjacentes aos dados e dos mecanismos que essas relações representam. Os estudiosos que utilizam as técnicas de rede invocam constructos teóricos tais como poder, dependência de recursos, cooptação, informação e confiança para explicar as estruturas sociais que emergem de suas análises. Esses mecanismos são compartilhados com a teoria institucional e com outras teorias que são relevantes para a sociologia dos mercados. Os teóricos institucionais se interessam pela maneira como fenômenos no âmbito dos campos se difundem para torná-los isomórficos, com frequência por meio de redes sociais (Davis, 1991). Os performativistas têm explicitamente conectado sua abordagem à teoria de redes no 
que Callon (1998) chama de abordagem do atorrede. A abordagem do ator-rede vê não apenas humanos, mas também objetos e artefatos, técnicas e ideias como agentes imersos em redes de relações de cálculos. Adicionalmente, as abordagens performativistas se sobrepõem à teoria institucional no que diz respeito ao seu interesse na forma como produtos são criados e vendidos, e no modo como as culturas locais de determinados mercados formam o que os institucionalistas chamam de institucionalização de mercados particulares.

Embora essas três abordagens abranjam uma grande parte do trabalho em sociologia dos mercados, elas não são, de modo algum, exaustivas. Além de considerar essas perspectivas específicas com o objetivo de extrair o que os sociólogos aprenderam sobre os mercados e o que falta ser resolvido, consideramos, nesta revisão, até que ponto esses grupos teóricos distintos oferecem representações incompletas da estruturação social dos mercados. A divisão do campo em redes, instituições e performatividade exclui outras perspectivas teóricas que também deveriam estar no cerne da reflexão sobre os mercados como estruturas sociais. Enfocamos duas abordagens importantes que têm sido pouco consideradas na literatura: a economia política e a ecologia populacional.

A economia política liderou o pensamento sobre as ligações entre Estados, legislação e mercados e a emergência histórica de sistemas de governança. A literatura sobre o estudo comparado dos arranjos capitalistas e seus efeitos sobre resultados variados, incluindo o desenvolvimento econômico, é parte e parcela da Sociologia dos Mercados. A teoria institucional é a abordagem que mais frequentemente incluiu a economia política em suas análises. Ela enfoca o papel dos governos e da legislação na criação de aspectos particulares dos mercados, como, por exemplo, os tipos de aliança e as formas de cooperação que são reconhecidos como legais, ou formas de direito de propriedade (Campbell; Lindberg, 1990, Carruthers; Ariovich, 2004). No entanto, os teóricos das redes e os estudiosos interessados na performatividade geralmente ignoraram os possíveis efeitos do governo e da legislação, assim como a influência das relações preexistentes entre os proprietários das firmas, gerentes, trabalhadores e governo sobre os mercados, o que faz com que sua apropriação de mercados específicos fique incompleta.

A ecologia populacional é o ramo da teoria organizacional que lida mais diretamente com os efeitos da competição sobre a produção dos mercados. Estudiosos que usam essa abordagem se inspiraram nas análises institucionais e de rede (Baron; Hannan; Burton, 1999; Haveman; Rao, 1997), mas a ecologia populacional não aparece no cerne da sociologia dos mercados, principalmente porque desenvolveu um vocabulário e um conjunto de métodos que não são de fácil tradução para a maior parte das abordagens da estrutura social. Isso é uma pena, porque muitos desenvolvimentos na ecologia populacional caminharam no mesmo sentido das outras abordagens. Mostramos aqui como muitas ideias na ecologia populacional foram expostas em linguagem diferente nas demais abordagens e argumentamos que os insights dessa corrente deveriam ser mais explicitamente acrescentados no pensamento acadêmico sobre a estruturação social dos mercados.

Uma vez que se constata a similaridade entre as ideias encontradas na literatura, incluindo as áreas de contribuição menos reconhecidas, permanece certo número de problemas interessantes relacionados às diferenças teóricas. Estudiosos na tradição performativista apresentam sua perspectiva como uma crítica aos modos predominantes de entendimento dos mercados. Sua ideia básica é que a ação econômica está relacionada ao cálculo e ao fato de que a forma como as qualidades dos bens são calculadas (i. e., a facilidade com que se podem calcular os bens, a capacidade de fazer cálculo dos atores e a interação entre eles e o ato de troca) é crucial para a compreensão da estrutura dos mercados. Esses estudiosos argumentam que tanto as ferramentas que os atores têm à sua disposição para interpretar e definir seus mundos eco- 
nômicos, como a forma como organizam a interação relacionada à troca, são criadas e implementadas por meio das formas pelas quais a atividade econômica deveria operar e opera de fato. Nós interpretamos o argumento da performatividade como uma tentativa de inserir os entendimentos culturais no cerne da construção social dos mercados.

Uma segunda discordância se foca nas ligações entre os produtores e consumidores. Muitas análises de mercados se focam exclusivamente nos produtores e em suas relações de competição. Aqui, dá-se atenção à maneira como as estruturas sociais resolvem as diversas formas de dependência de recursos ou fazem a mediação da competição. No entanto, outros estudiosos que enxergam os elos entre produtores e consumidores como centrais na produção de mercados enfatizam o papel da confiança e da cultura (i. e., significados comumente compartilhados sobre o produto, sua moralidade e sua utilidade) naquelas relações como algo que tem um papel-chave na compreensão dos processos mercantis. Granovetter (1985) argumentou anteriormente que o principal propósito da imersão nos mercados era aumentar a confiança entre compradores e vendedores. Zelizer (1983, 1994, 1997) incorporou a relação entre produtores e consumidores em direção diversa. Seu argumento é que consumidores devem ser convencidos não apenas da utilidade dos produtos que compram e da confiabilidade daqueles que os vendem, como também da moralidade do produto. Sua abordagem, mais orientada para a dimensão cultural, alerta os estudiosos para o problema de enquadrar produtos de modo que os consumidores os vejam não somente como úteis, mas também de acordo com seus valores.

Uma terceira fonte de discordância é que alguns estudiosos veem as estruturas de mercado em formação ou em equilíbrio, enquanto outros argumentam que os mercados estão sempre mudando. A possibilidade de uma definição sociológica para o equilíbrio de mercado é intrigante. White (1981), por exemplo, definiu mercado como uma “estrutura de papéis reprodutível”. Essa ideia implica que os processos sociais que ocorrem quando um mercado se forma são diferentes dos processos sociais que ocorrem uma vez que surge um conjunto mais estável de relações sociais. A ecologia populacional possui uma teoria implícita de que poderia ser chamada de equilíbrio pontuado. No momento inicial de um mercado, há frequentemente um período de confusão e mudança seguido de alguma estabilidade e, talvez, um segundo momento de confusão. A visão alternativa é que os mercados são sempre fluidos, com produtos, processos e vantagem mudando constantemente. Aqui, as soluções baseadas em equilíbrio para o problema do que os outros atores do mercado vão fazer nunca se confirmarão (Nelson; Winter, 1982). Essas perspectivas diferenciadas para a dinâmica do mercado são importantes porque elas pressupõem formas bastante diferentes de olhar para a estruturação social de um mercado. Por um lado, se os atores, tentando encontrar uma posição em um mercado, podem produzir coletivamente equilíbrio, então o objetivo dos atores nesse mercado se torna preservar aquela ordem. Isso implica relações de poder e dominação nos mercados. Por outro lado, se as firmas estão resignadas a viver em um mundo no qual reproduzir a sua posição no mercado não é possível, nesse caso, as relações sociais se tornam arranjos temporários que permitem que se busque informação ou se garanta tecnologia de ponta. Uma vez que a mudança é constante, os parceiros são escolhidos em função de sua utilidade e, quando a utilidade acaba, buscam-se novos parceiros.

Finalmente, os sociólogos, em geral, têm uma relação complicada com o problema da eficiência de um dado arranjo social. $\mathrm{O}$ fato de haver tantos tipos de relações sociais nos mercados conduziu ao argumento de que essas relações existem para resolver problemas de mercado, tais como custos de agência (Fama; Jensen, 1983) e custos de transação (Williamson, 1985), assim como para promover a confiança entre compradores e vendedores. Alguns sociólogos parecem estar preparados para aceitar que as estruturas sociais poderiam ser eficientes (Baker, 1984; Uzzi, 1996). Desse ponto de vista, as es- 
truturas sociais nos mercados operam para reduzir os custos de informação, permitir que as firmas saibam o que a competição está fazendo, permitir que os agentes do mercado confiem uns nos outros e reduzir a dependência de recursos. Essas estruturas sociais proveriam informação às firmas, permitindo-lhes aprender e se adaptar e, ao fazê-lo, competir de forma eficaz. No entanto, outros estudiosos são céticos quanto a essa questão (Fligstein, 1990; Podolny, 1993). Para eles, as estruturas sociais podem operar no sentido de mitigar os efeitos da competição. Nessa perspectiva, as firmas tentam controlar os mercados usando seu tamanho, sua tecnologia e seu acesso ao governo para promover uma hierarquia entre incumbentes e desafiadores. As empresas incumbentes usam suas vantagens para sinalizar a seus principais competidores o que farão para defender a ordem de mercado existente. Para esses estudiosos, a estrutura social do mercado existe para produzir tal ordem. Uma maneira de progredir nessa questão é problematizar a eficiência. A sociologia dos mercados nos dá ferramentas para decidir se um dado conjunto de estruturas sociais protege os incumbentes ou, ao invés disso, fomenta o crescimento econômico e a competição.

Nesta revisão, discutimos as raízes intelectuais da sociologia dos mercados e a maneira como o campo se desenvolveu a partir de problemas colocados em campos vizinhos. Então, examinamos a cristalização das principais ideias na sociologia dos mercados e, ao fazê-lo, discutimos o que sabemos. Finalmente, consideramos quais são as verdadeiras opiniões divergentes e sugerimos caminhos para pesquisa futura.

\section{RAÍZES CONTEMPORÂNEAS DA SOCIOLO- GIA DOS MERCADOS}

Diversas boas revisões bibliográficas foram escritas sobre a história intelectual da sociologia dos mercados como um campo (Biggart; Beamish, 2003; Foucaude-Gourrinchas, 2007;
Krippner, 2001; Lie, 1997; Smelser; Swedberg, 1994; Trigilia, 2002). Nosso objetivo, nesta seção, é reunir essa literatura de uma maneira nova. Ao invés de enfocar as raízes da sociologia dos mercados na teoria clássica, enfocamos os campos de estudo contemporâneos que contribuíram para fermentá-la intelectualmente. Em particular, traçamos a influência que campos próximos tiveram sobre a sociologia dos mercados.

Novos campos de pesquisa social são construídos relacionando-se com outros campos. Quando estudiosos, trabalhando dentro de um campo, encontram-se em diálogo com outros que focalizam problemas semelhantes em outros campos, por vezes, um novo campo de pesquisa é criado. No final de contas, novos campos envolvem estudiosos que tomam emprestadas as perspectivas uns dos outros, assim como procuram mecanismos e modelos que poderiam explicar novos objetos de investigação. Nesse caso, a economia política, a sociologia dos mercados de trabalho e a teoria organizacional pensaram pioneiramente sobre a sociologia dos mercados, e a fertilização cruzada de ideias nesses campos formou os insights básicos que conduziram ao seu estabelecimento como um campo autônomo. Estudiosos em todos esses campos levantaram dúvidas sobre a capacidade de a economia dar conta do que se passa nos mercados. Essencialmente, esses campos descobriram que os agentes atomizados, orientados pelo preço, com informação perfeita e simétrica, tal como presumido pela teoria neoclássica, não pareciam existir empiricamente. As relações sociais pareciam ser cruciais no funcionamento dos mercados e de seus agentes de diferentes maneiras. Embora todos esses subcampos tenham começado a criticar a economia, fizeram-no de perspectivas diferentes e por razões diferentes, tendo suas críticas internas às lógicas desses campos se constituído nos primeiros passos em direção à criação de uma sociologia dos mercados contemporânea. É útil entender esses debates de modo que se possam compreender as diferentes vozes teóricas dentro da sociologia dos mercados. 
A economia política dos anos 1960 era dominada pela teoria da modernização. Essa perspectiva buscou explicar a maneira como países economicamente subdesenvolvidos poderiam se desenvolver, seguindo a trilha das nações industrializadas. Em geral, os estudos nessa vertente enfocaram a maneira como atributos culturais e estruturais similares nas nações em desenvolvimento, caracterizados como tradicionais, poderiam ser superados, de modo a emular os modelos institucionais dos países desenvolvidos e promover crescimento econômico (Eisenstadt, 1973; Kerr; Dunlop; Harbison, 1960; Lerner, 1963; Rostow, 1961). As críticas da teoria da modernização na economia política levaram os pesquisadores a novas perspectivas sobre o desenvolvimento e o estudo comparativo dos capitalismos.

Os estudiosos nesse campo se voltaram para A grande transformação, de Polanyi (1957), em busca de inspiração (Block; Evans, 2005, para uma revisão da literatura sobre as ligações entre Estados e mercados). Polanyi argumentou não apenas que a criação dos mercados requeria a existência dos Estados, como também que a formação de mercados capitalistas produziria o caos social. Como resposta, ele sugeriu que os governos deveriam intervir nos mercados de modo a estabilizá-los e prover proteção social aos trabalhadores, assim como regras para guiar a interação entre os grupos de capitalistas. As formas de fazêlo seriam necessariamente contingentes, de modo que a variação institucional histórica poderia explicar a variação entre nações nas estruturas dos mercados. A rejeição da convergência teleológica das instituições em direção aos modelos ocidentais, conforme presumiam os pressupostos econômicos em boa parte da teoria da modernização, levou os estudiosos a olharem para a forma como as instituições do capitalismo em movimento (leis, regulações e práticas institucionalizadas) vieram regular a relação entre firmas, proprietários, governos e trabalhadores com modos que produziram diferenças fundamentais nas estruturas de mercado dessas sociedades.

À medida que os projetos de desenvolvi- mento avançaram, primeiro no Japão e depois na Coreia, os estudiosos se debruçaram sobre a forma como os arranjos locais entre governos, elites econômicas e trabalhadores ofereceram as condições para o crescimento econômico tanto em sociedades desenvolvidas como em desenvolvimento (Amsden, 1991; Aoki, 1990; Dore, 1973, 1987, 1997; Evans, 1995; Johnson, 1982; Wade, 1990). Enquanto isso, o estudo comparativo dos capitalismos revelava que a relação entre esses grupos mostrava notável diversidade e refletia trajetórias históricas, culturais e nacionais (Campbell; Hollingsworth; Lindberg , 1991; Campbell; Lindberg, 1990; Fligstein; Choo, 2005). Essa perspectiva sugeriu que governos, trabalhadores e capitalistas produziam estruturas de mercado que diferiam entre os países (Albert, 1993; Berger; Dore, 1996; Boyer; Drache, 1996; Hall: Soskice, 2001; Hollingsworth, 1994). Os mercados não eram dados por agentes externos; ao contrário, refletiam a construção social e política de cada sociedade, de modo que a história e a cultura em torno das relações de classe e os vários tipos de intervenção por parte dos governos produziram ordens institucionais únicas.

A teoria institucional, em sua maior parte centrada nas escolas de negócios, preocupou-se em compreender a forma como os gestores das firmas leem as demandas de seus ambientes e ajustam suas estruturas organizacionais em linha com aquelas contingências (Miles, 1980). Embora a teoria gerencial rejeitasse alguns dos princípios da economia (March; Simon; Guetzkow , 1958, Simon, 1957), tais como informação perfeita e racionalidade perfeita, o objetivo da firma continuou sendo ajustar-se ao mundo da competição, como pressuposto pela economia. A crítica ao foco da teoria gerencial nos processos organizacionais internos levou os teóricos das organizações a duas direções.

Hannan e Freeman (1977) argumentaram que os estudiosos vinham prestando muita atenção aos processos adaptativos nas organizações. Alternativamente, eles estudaram a emergência das formas organizacionais no nível das populações. Seu pressuposto era de que as oportunida- 
des de mercado é que conduziam ao nascimento das firmas. Mas o caráter do mercado - isto é, os recursos que poderiam ser explorados pelas firmas-determinaria as formas organizacionais que sobreviveriam. Do ponto de vista de Hannan e Freeman, o principal problema que a competição criaria para as firmas seria a dependência de recursos (Pfeffer; Salancik, 1978). Muitas firmas não seriam capazes de conseguir os recursos necessários para sobreviver, e isso levaria a altas taxas de fracasso no início dos projetos de abertura de mercado. A despeito do foco da ecologia populacional na competição, os estudiosos nesse campo se deram conta de que a formação das fronteiras do mercado seria um processo social e que a formação de nichos, com frequência, refletia a habilidade das firmas no sentido de segregarem seus mercados (Carroll, 1985; Hannan; Freeman, 1988). As firmas dependem de legitimidade e choques externos em um nicho, como a introdução de uma nova lei, o que pode ter efeitos profundos sobre a dinâmica de um nicho (Ranger-Moore; Banaszak-Holl; Hannan, 1991; Ingram; Rao, 2004; Haveman; Rao, 1997). Recentemente, representantes da ecologia populacional começaram a enfocar a maneira como as firmas formam sua identidade e como tais identidades formam mercados (Carroll; Swaminathan, 2000).

Enquanto a ecologia populacional via o ambiente da firma como "duro" e, por isso, a escassez de recursos como o principal mecanismo de sua seleção, a teoria institucional sugeria que o ambiente seria, pelo menos em parte, uma construção social. Scott e Meyer (1982) chamaram esses ambientes de "setores" e descreveram o ambiente socialmente construído das firmas como uma função de todas as outras organizações que poderiam, de algum modo, influenciar uma organização particular. Eles incluíram governos, fornecedores, trabalhadores e clientes como parte dessa construção social. Notamos que setores que reúnem todas as partes interessadas parecem bastante similares ao conjunto de atores que a economia política enfoca, isto é, firmas, governos e trabalhadores. DiMaggio e Powell (1983) estenderam esses argumentos e chamaram tais ambientes de "campos organizacionais", um termo que se disseminou. A metáfora do campo implica que as firmas se controlam mutuamente, se engajam em comportamento estratégico umas em relação às outras e se observam mutuamente em busca de dicas do que constitui um comportamento bem-sucedido. O principal foco de DiMaggio e Powell (1983) estava na forma como as firmas, em campos organizacionais, viriam a se parecer umas com as outras por meio de processos isomórficos miméticos, coercitivos e normativos.

Em 1981, White ofereceu uma visão sociológica do que ele achava que as firmas fazem nos mercados. $\mathrm{O}$ argumento central do autor era de que as firmas, em mercados de produção, posicionavam suas organizações umas em relação às outras. Usando o preço e a qualidade relativa de seus produtos, elas sinalizavam umas para as outras que tipo de produtor queriam ser. Essa sinalização produz o que White chamou de um mercado, o qual ele definiu como estrutura de papéis reprodutível. A visão de White combina alguns dos insights da economia sobre a forma como os preços podem ser usados como sinais (Spence, 1974), com o foco da sociologia organizacional na construção de campos ou nichos.

Enquanto os estudiosos organizacionais examinaram os processos sociais que estruturam as relações entre organizações, os estudiosos da estratificação e dos mercados de trabalho desenvolveram um novo olhar sobre o papel das firmas na distribuição dos recursos. Durante os anos 1960 e 1970, a principal abordagem que os sociólogos usavam para examinar os mercados de trabalho era o modelo da busca de status. Essa visão enfocava a forma como os indivíduos eram separados em um conjunto mais ou menos fixo de posições, de acordo com suas características pessoais, tais como origem familiar, educação, gênero e raça (Blau; Duncan, 1967; Hauser Featherman, 1977). Na medida em que o modelo da busca de status vê as ligações entre os indivíduos e seus resultados socioeconômicos como, principalmen- 
te, uma função de suas características pessoais, o problema da demanda pelo trabalho, e, assim, o papel da firma, estava fora do campo de visão.

Durante os anos 1970, os estudiosos se interessaram em duas outras questões: como a estrutura dos empregos afeta os padrões de mobilidade individual e qual é o processo real por meio do qual as pessoas se combinam aos empregos. Os sociólogos responderam essas perguntas considerando o papel das firmas no processo de recrutamento e as relações sociais no processo de combinação. O novo estruturalismo modelou a forma como as empresas afetam a distribuição de recompensas (Baron; Bielby, 1980; Hodson, 1983; Kalleberg; Griffin, 1980). Chains of Opportunity, de White (1970), elaborou a maneira como cadeias de empregos em aberto ajudavam a produzir a distribuição de trabalhadores e recompensas. Getting a job, de Granovetter (1974), discutiu a forma como se dava a combinação entre as pessoas e os empregos. Ele introduziu a ideia de que as redes sociais fazem a mediação entre empregadores e empregados. Ambos, White e Granovetter, lideraram o uso da análise de redes como uma maneira de entender a estrutura social que liga empregadores e empregados.

\section{ACORDOS NA SOCIOLOGIA DOS MERCADOS}

No cerne da sociologia dos mercados está a tentativa de incluir os sociólogos no estudo do mundo econômico, inserindo a teoria social e a maneira como funciona a vida social em geral nas firmas, mercados e indústrias. Como sugere nossa revisão, as peças teóricas para a construção da sociologia dos mercados estavam prontas em 1983. Nesse momento, já existia uma teorização acerca do funcionamento das firmas, reconhecendo-se o papel das estruturas sociais na competição entre as empresas e no processo de sua articulação com fornecedores, clientes, trabalhadores e governos, assim como a variação dessas estruturas por meio de mercados, períodos históricos e países. A declaração de Granovetter (1974) de que a vida econômica sempre fora inserida na vida social provou ser o enquadramento intelectual que justificava abrir as comportas da pesquisa, trazendo uma enorme quantidade de estudiosos armados com ideias sociológicas para o estudo das atividades de mercado e, ainda mais importante: engajarem-se num debate comum.

O que começou em seguida foi a exploração dos mercados de produto e trabalho. Os estudiosos se debruçaram sobre casos concretos e tentaram aplicar essas ferramentas para dar conta dos resultados. A sociologia dos mercados tem sido usada para explicar muitos aspectos dos mercados. Alguns estudiosos demonstraram como as relações sociais nos mercados produzem preços mais estáveis (Baker, 1984; Uzzi, 1997; Uzzi; Lancaster, 2004). Outros enfocaram a maneira como a estruturação social dos mercados afeta o nascimento e morte de pequenas firmas (Stuart; Hoang; Hybels, 1999; Stuart; Sorenson, 2003). Outros mais têm observado a inovação e a difusão de novas estratégias de mercado, tais como novos produtos, inovações financeiras, ou mudanças nas organizações, tais como diversificação dos produtos, expansão geográfica e integração vertical, assim como mudanças relacionadas à subunidade que controla a firma (Ahmadjian; Robinson, 2001; Beckman; Haunschild, 2002; Davis, 1991; Davis; Iekmann; Tinsley, 1994; Fiss; Zajac, 2004; Fligstein, 1985, 1991; Gulati; Westphal, 1999; Haunschild, 1993; Hirsch, 1986; Ocasio; Kim, 1999; Westphal; Zajac, 1998; Zorn, 2004; Zuckerman, 1999, 2000). A exploração de todas as ligações possíveis entre firmas, fornecedores, clientes, governos e trabalhadores levou os estudiosos a postularem diversos mecanismos de imersão. A literatura se agrupou na tentativa de generalizar esses casos e começou a elaborar diferentes maneiras de pensar sobre o problema da imersão social dos mercados. Krippner (2002) argumentou que o termo imersão se revelou vagamente definido. Argumentamos que esse era o caso no início. Estudiosos que estavam se voltando para o problema de pontos de vista muito diferentes examinaram diferentes formas pelas quais as transações econômi- 
cas seriam socialmente estruturadas.

A variedade de abordagens tornou a formulação de uma definição sociológica para os mercados uma tarefa difícil. Para a teoria neoclássica, os mercados implicam a simples troca de bens e serviços entre atores. Essas trocas são geralmente entendidas como passageiras, sendo o preço (i. e., a quantidade de uma mercadoria que é trocada por outra usando um meio generalizado de troca, i. e., dinheiro) determinado pela oferta e demanda da mercadoria. Do ponto de vista da sociologia dos mercados, o problema é que esse tipo de troca já demonstra uma boa dose de estrutura social. Atores do mercado têm de se encontrar. $\mathrm{O}$ dinheiro precisa existir de modo a permitir que os atores do mercado possam fazer mais do que regatear bens não equivalentes. Os atores precisam saber qual é o preço. Por trás de toda a troca está o fato de que tanto os compradores quanto os vendedores creem que não serão trapaceados. Essa crença em geral pressupõe mecanismos informais (i. e., conhecimento pessoal sobre o comprador e o vendedor) e formais (i. e., a lei) que governam a troca. Adicionalmente, os atores do mercado são, com frequência, organizações, implicando que a dinâmica organizacional influencia a dinâmica do mercado. Para os sociólogos, a troca mercantil implica todo um pano de fundo de arranjos sociais dos quais a economia mal toma conhecimento.

No entanto, a sociologia dos mercados faz mais do que apenas questionar a imersão institucional de um mercado anônimo. Ela está preparada para abrir a caixa preta da troca, competição e produção. Os sociólogos partem da constatação de que os atores do mercado estão envolvidos em relações sociais cotidianas uns com os outros, relações baseadas em confiança, amizade, poder e dependência. Para a sociologia dos mercados moderna (Durkheim, 1964), ${ }^{5}$ a troca social não estruturada, aleatória, encerrada em si mesma e anônima não é um mercado. Ao invés

\footnotetext{
${ }^{5}$ Ironicamente, os estudiosos da sociologia dos mercados quase nunca citam Durkheim. No entanto, pode-se argumentar que quase todas as ideias importantes nesse campo têm raízes durkheimianas. Durkheim (1964) reconhe-
}

disso, os mercados pressupõem espaços sociais onde trocas repetidas ocorrem entre compradores e vendedores sob um conjunto de regras formais e informais que governam relações entre competidores, fornecedores e clientes. ${ }^{6}$ Esses campos operam de acordo com entendimentos locais e regras, além de convenções formais e informais que guiam a interação, facilitam o comércio, definem os produtos que são produzidos, e, de fato, são constitutivas dos produtos, assim como proveem estabilidade para compradores, vendedores e produtores. Esses mercados dependem de governos, leis e entendimentos culturais mais amplos nos quais se baseia a atividade mercantil. A primeira coisa que uma sociologia dos mercados sugere é que os atores do mercado vão desenvolver estruturas sociais para mediar os problemas que encontram na troca, competição e produção. Nós discutimos cada um deles em seu turno e delineamos as principais contribuições de cada perspectiva com respeito à maneira como os atores do mercado resolvem tais problemas e, ao fazê-lo, constroem seus mundos e neles navegam.

Muitos aspectos das relações de troca nos mercados foram examinados pelos sociólogos. A teoria institucional sugere não apenas que a troca mercantil contratual depende de que o Estado defina e sancione as regras, mas também que o Estado possa definir que tipos de produtos são apropriados para a troca. Adicionalmente, a estrutura interna do Estado, na condição de definidor de regras e regulador, pode influenciar os tipos de pro-

ceu o papel crucial do Estado e da lei na troca capitalista, prefigurando a preocupação da economia política com esses temas. Ele também reconheceu que havia uma base não contratual dos contratos, o que implicava serem as relações pessoais necessárias para que as pessoas honrassem os contratos. Finalmente, na divisão do trabalho, o principal mecanismo que dirigia a sociedade moderna era a competição. O argumento de Durkheim (1964) era de que as pessoas dividiam as tarefas para diminuir sua competição com outras pessoas. Pode-se argumentar que esse mecanismo está no cerne da visão da ecologia populacional, segundo a qual os nichos de mercado são criados pela competição, e nos argumentos de White (1981) sobre a maneira como as firmas evitam a competição ao sinalizar para qual parte do mercado irão produzir.

${ }^{6}$ Claro que algumas das identidades de compradores e vendedores mudam com o tempo. Adicionalmente, compradores e vendedores mais periféricos vêm ao mercado, partem e não retornam. Mas os jogadores que estão no cerne do mercado, os produtores e consumidores de maior porte, criam uma estrutura social. 
dutos que os Estados permitem que possam ser trocados e as regras que embasam e envolvem a troca (Carruthers; Halliday, 1998; Delaney, 1992; Schneiberg; Soule, 2005). Compradores e vendedores, em geral, também se conhecem e estão envolvidos em trocas repetidas. Teóricos de redes têm enfatizado o papel que elas desempenham no sentido de gerar a confiança entre compradores e vendedores, o que torna a troca possível (Granovetter, 1985). Os sociólogos da cultura têm se debruçado sobre a forma como relações de troca específicas são profundamente construídas pelos significados culturais por trás dos produtos que são comprados e vendidos (Zelizer, 1983). Finalmente, os sociólogos geralmente acreditam que o poder influencia as relações sociais e, portanto, as relações de mercado (Pfeffer; Salancik, 1978). As relações de troca podem ser profundamente influenciadas, por um lado, pelo poder relativo dos atores sobre a oferta e demanda do que está sendo trocado e, por outro, pela sua dependência relativa do que está sendo trocado. Essa concepção de poder nos mercados é geralmente referida como dependência de recursos e tem sido descrita e empregada em uma variedade de formas por muitos sociólogos.

Dependência de recursos é um constructo geral utilizado na sociologia dos mercados. A ideia começa com a premissa de que, em qualquer troca social, um lado da troca pode ser mais dependente do que o outro em relação ao que está sendo trocado (Emerson, 1962). Se um lado da troca for muito mais dependente do que o outro, ele estará ou mais propenso a ter de obedecer aos ditames do fornecedor-cliente, ou então a correr o risco da extinção. ${ }^{7}$ Essa ideia tem grande generalidade quando se trata de examinar a troca. Então, por exemplo, as firmas precisam obter financiamento, garantir a matéria-prima de seus produtos e de seu trabalho, assim como estabelecer relações com seus competidores, governos e clientes. A literatura empírica tem mos-

${ }^{7}$ Note-se que na Economia Neoclássica, presume-se que a troca se dá entre iguais. Se os compradores e vendedores têm informação perfeita sobre preços, então os compradores não irão pagar mais do que eles precisam e os vendedores não irão pedir além disso. trado que aquele em condições de deter o poder nessas relações varia com base na natureza da dependência de recursos e do mercado particular em estudo.

Embora muitos estudiosos que estudaram interações baseadas em trocas tenham enfocado o uso de metodologias de análise de rede sociais, eles, com frequência, postulam a existência de mecanismos que envolvem dependência de recursos. Por exemplo, Lincoln, Gerlach e Ahmadjian (1996) demonstram a forma como os elos de propriedade entre as firmas japonesas afetam a habilidade das firmas proprietárias em ditar as ações de suas subsidiárias. Formar relações com os principais fornecedores de uma dada empresa também pode ser uma forma de cooptar tal dependência. Burt (1980) demonstra a forma como as corporações norte-americanas usam estrategicamente a participação em conselhos de administração para trazer representantes de firmas das quais outra firma particular é dependente para a obtenção de recursos. Stuart, Hoang, e Hybels (1999) demonstraram que obter dinheiro de ofertantes de capital de risco afeta a probabilidade de que uma firma particular sobreviva. Eles interpretam tais conexões não somente do ponto de vista da garantia do financiamento, mas também do ponto de vista da garantia de legitimidade para uma firma start-up particular, permitindo, dessa forma, que ela esteja mais apta a contar com trabalhadores e clientes. Em suma, um dos objetivos dos laços entre fornecedores e clientes é controlar a dependência de recursos e aumentar a probabilidade de sobrevivência de uma firma. Aqui, os teóricos de redes estão enraizados no campo mais geral, que inclui a ecologia populacional e a teoria institucional, na medida em que se preocupam com a maneira como a dependência de recursos afeta a legitimidade e sobrevivência das firmas.

Os teóricos de redes e os psicólogos sociais experimentais postulam um mecanismo adicional que liga compradores e vendedores: a confiança (Cheshire; Cook, 2004; Granovetter, 1985, 2005; Kollock, 1994, 1999; Uzzi, 1996; Yamagushi; 
Cook, 1993). O principal argumento de Granovetter sobre a imersão é que, quando se tem fortes laços entre os atores durante muito tempo, pode-se confiar que, em qualquer transação particular, as pessoas tenderão a ser menos propensas a trapacear. A literatura experimental demonstrou que a confiança importa mais em situações nas quais há grande dose de incerteza sobre as qualidades do produto que está sendo trocado (Cheshire; Cook, 2004; Kollock, 1994). Kollock (1999) examinou a maneira como a reputação funciona no sentido de aumentar a confiança entre os atores. Embora a confiança não seja um mecanismo importante na ecologia populacional, tampouco na teoria institucional, ela certamente se conecta, de algum modo, a essas teorias. Julgar o quanto outro ator é confiável é mais do que ter um laço de rede de longo prazo com ele. Confiança também está relacionada a poder e dependência de recursos. As firmas trabalham para reduzir a incerteza e a dependência de recursos na medida em que escolhem parceiros que elas sabem ser confiáveis ou que outros reconhecem como confiáveis.

Os estudiosos interessados na cultura e no consumo também enfocaram a troca nos mercados. A sociologia do consumo (Bourdieu, 1984; Csikszentmihalyi; Rochberg-Halton, 1981; Slater, 1997; Zelizer, 1983, 1994, 1997; para artigos de revisão de literatura, ver Zelizer, 2005; Zukin; Maguire, 2004) enfoca o significado dos produtos para as pessoas e a maneira como elas usam o dinheiro e o mercado para estabelecer significados, status e moralidade. Para esses estudiosos, a cultura está profundamente implicada na troca mercantil. Produtos são objetos culturais imbuídos de significados baseados em entendimentos comuns e são eles próprios símbolos ou representações desses significados. O consumo reproduz as vidas materiais dos consumidores e os provê de meios para expressar suas identidades e afiliações a grupos de status. Porém, são mais importantes para esses estudiosos os significados ligados aos produtos negociados por consumidores e produtores, os quais moldam as relações interpessoais de trocas mercan- tis e, por sua vez, são moldadas por elas.

Embora a troca caracterize a relação entre comprador e vendedor nos mercados, a competição caracteriza a relação entre produtores. ${ }^{8}$ Os sociólogos argumentam que mercados competitivos se apresentam aos produtores como problemas a serem resolvidos, e eles o fazem usando estratégias de cooperação, combinação e diferenciação de produtos. Os graus em que um mercado é competitivo - os produtores podem cooperar e fazer combinações, assim como a maneira como os direitos de propriedade são organizados - são todos regulados pelo governo. Embora os produtores tentem usar uma variedade de estratégias para controlar a competição, o governo define as formas aceitáveis de relacionamento que os produtores podem estabelecer entre si e regula a competição na medida em que reage às estratégias empregadas pelas firmas.

A ecologia populacional, a teoria de redes e a teoria institucional reconhecem que a diferenciação dos produtos é um dos principais mecanismos que as empresas têm para controlar a competição. Isso funciona de duas maneiras. Se as empresas podem escolher em qual parte do mercado elas querem competir, então elas podem ir até onde os competidores não vão. Carroll (1985), chamando esse processo de partição por nichos, demonstrou que as microcervejarias são capazes de criar um nicho de rápido crescimento para si, mesmo enquanto as grandes cervejarias estão aumentando seu controle sobre a indústria de cerveja (Carroll; Swaminathan, 2000). White (1981) argumentou no mesmo sentido. Para ele, os mercados são estruturas de papéis reprodutíveis, nas quais as firmas decidem entre os preços que elas querem cobrar por um bem e a qualidade daquele bem que elas produzem. Ao fazer isso, decidem em que parte do mercado elas querem estar.

Leifer e White (1987) demonstraram a ma-

${ }^{8}$ As relações com competidores também podem ser caracterizadas em termos de dependência de recursos. No modelo de White (1981), quando as firmas sinalizam sua intenção de entrar numa parte diferente do mercado, elas estão tentando controlar suas interdependências. 
neira como isso funciona no mercado de pizzas congeladas. White (2002), posteriormente, identificou esse mecanismo como uma forma de produzir mercados inteiramente novos. Se os produtos se tornam suficientemente diferenciados, então eles não estarão mais competindo. A perspectiva de White (2002) pode facilmente ser traduzida para a linguagem da ecologia populacional. White (2002) argumenta que os mercados se diferenciaram por meio das firmas ocupando posições diferentes no nicho e, na medida em que aquelas firmas não estiverem, de fato, competindo, isso poderia resultar numa partição do nicho ou, na linguagem de White (2002), na criação de novos mercados.

A diferenciação de produtos pode também ajudar na estabilidade da firma, na medida em que espalha as pressões competitivas por meio de mercados de produtos múltiplos. Se as firmas decidem produzir diversos produtos, a queda em um mercado particular não ameaçará a existência da firma, porque ela não será totalmente dependente de recursos em relação à troca de um produto. A ecologia populacional notou esse processo, descrevendo a tática de diversificação como uma estratégia generalista (Hannan; Freeman, 1977). Fligstein (1990) chega à mesma conclusão a partir do ponto de vista da teoria institucional. Ele demonstra que a diferenciação de produtos nas corporações norte-americanas começou como uma estratégia de marketing nos anos 1920 e foi liderada por grandes firmas para estabilizarem sua estrutura como um todo. Durante a grande depressão dos anos 1930, as maiores corporações produziam tantos tipos diferentes de produtos quanto fosse possível, de modo a continuar a existir em condições tão adversas para os negócios.

Além de produzir diferenciação, os produtores também buscam cooperar e fazer combinações para reduzir as pressões competitivas. $\mathrm{Na} \mathrm{li-}$ teratura econômica mais antiga sobre organização industrial, um pequeno número de firmas que dominam um mercado age para reduzir a competição daquele mercado. As firmas desafiantes não podem oferecer preços mais baixos que seus "irmãos" maiores, porque as grandes firmas podem durar mais que qualquer competidor em uma guerra de preços. Podolny (1993), um teórico de redes, chama esse tipo de estrutura de hierarquia de status. Ele estuda a forma como bancos de investimento formam tal hierarquia, que é montada, principalmente, pelo tamanho e prestígio dos maiores bancos. Esses bancos obtêm os negócios de maior volume e reproduzem seu lugar naquela estrutura na medida em que podem bater seus competidores, se necessário. Fligstein (1996), em um veio mais institucionalista, chama isso de estrutura incumbente-desafiadora. Ele argumenta que tais estruturas se reproduzem na medida em que os incumbentes usam seu poder de mercado para sustentar sua vantagem num dado mercado, ao longo do tempo.

Embora os produtores possam tentar exercer poder de mercado por meio da criação de hierarquias, tal estratégia tem seus limites. Os governos regulam a competição (Ranger-Moore; Banaszak-Holl; Hannan,, 1991; Dobbin; Dowd, 2000; Fligstein, 1990; Haveman; Rao, 1997; Ingram; Rao, 2004; Ingram; Robinson; Busch, 2005), ao mesmo tempo em que afetam as oportunidades de expansão e sobrevivência das firmas. O papel do governo e da legislação na produção dos mercados foi reconhecido pelos campos da ecologia populacional, pelos institucionalistas e, obviamente, pela economia política. Esses grupos teóricos entendem que os governos podem tanto abrir oportunidades como criar constrangimentos para os mercados. Por exemplo, Hannan e Freeman (1987) demonstram como a legalização das atividades sindicais afetou a fundação e a sobrevivência daquelas associações organizacionais. Ranger-Moore, Banaszak-Holl e Hannan (1991) demonstram como a indústria de seguros, no século XIX, expandiu-se e contraiu-se na medida em que os reguladores mudaram seus papéis ao longo do tempo. Haveman e Rao (1997) demonstraram processos similares que operavam nas indústrias de poupança e empréstimos. Fligstein (1990) apresenta evidências de que o governo norte-americano desempenhou um papel preponderante no sentido de evitar a cartelização e 
monopolização das empresas norte-americanas no final do século XIX por meio da legislação antitruste. Ele também demonstra que o governo federal desempenhou um papel no sentido de fechar o movimento de fusões na década de 1960, por meio da perseguição severa às fusões de conglomerados. Dobbin (1994) demonstra a forma como políticas governamentais direcionadas às ferrovias, desde o início de sua formação, afetou sua organização em diferentes países. Dobbin e Dowd (2000) documentaram a forma como o governo teve papel importante nas ferrovias nos Estados Unidos. Campbell e Lindberg (1990) argumentaram que os direitos de propriedade estão no coração das relações entre governos e firmas (para uma revisão da literatura sociológica sobre direitos de propriedade, ver Carruthers e Ariovich, 2004).

A visão sociológica das relações entre produtores traz consigo a questão de quem esses produtores são e como eles tomam decisões sobre a produção. Do ponto de vista da economia neoclássica, pouco importa se os produtores são indivíduos ou organizações; o que importa é a função de produção e a combinação de capital e trabalho usada no processo produtivo (Shepard, 1970). Por outro lado, os sociólogos, há muito tempo, examinam as organizações como estruturas sociais. Alguns tomam a organização da firma individualmente como ponto de partida, porém a maioria concorda que as organizações têm dinâmicas internas complexas, importantes para o formato organizacional e para as estratégias que elas usam para resolver os problemas da competição e troca. Eles sinalizaram a competição dentro da firma, a cultura e as lutas de poder, além da influência ambiental, como importantes para a compreensão da estratégia da firma e, assim, para a estrutura dos mercados (Fligstein, 1990; Ocasio; Kim, 1999; Pfeffer, 1981; Pfeffer; Salancik, 1978).

O estudo da dinâmica interna das firmas e da forma como elas se relacionam com seus ambientes está enraizada na teoria organizacional. Embora muito do trabalho empírico, na sociolo- gia dos mercados, trate as firmas como unidades, os sociólogos estão, em geral, comprometidos, ao menos teoricamente, com a ideia de que sua dinâmica interna é importante (Bourdieu, 2005). Os dois aspectos-chave das firmas com os quais os estudiosos organizacionais têm estado mais preocupados são a estratégia e a estrutura (Miles; Snow, 1978). O desenho da organização é sua estrutura. Isso inclui linhas de autoridade e as relações formais e informais entre as posições na firma. Em paralelo, a estratégia se refere aos meios que a organização emprega para alcançar seus objetivos. As questões centrais colocadas em torno desses aspectos das organizações têm sido: de onde elas vêm e como se relacionam com as estruturas de mercado.

Embora as explicações econômicas para diversas estratégias e estruturas geralmente estejam centradas nos custos de transação, custos de agência ou aspectos da tecnologia utilizada pela firma na produção (Chandler Junior, 1962; Fama; Jensen, 1983; Williamson, 1985), os sociólogos têm enfatizado a natureza contingente dos objetivos da firma e a forma como a cultura e o background dos gestores influenciam sua estratégia e sua estrutura. Essa ênfase torna importantes as divisões dentro da firma e as trajetórias de carreira dos gestores. A forma como a firma divide suas funções e como ela conduz suas promoções internas e a luta política determina quem a gerencia, e, dessa forma, a perspectiva que irá dominar a sua estratégia. Por exemplo, Fligstein (1990) enfatizou que o fortalecimento dos gestores com background em vendas e marketing ou em finanças precedeu a adoção das estruturas multidivisionais e estratégias de diversificação de produtos. Processos de sucessão gerencial bem como a distribuição dos recursos e promoções estão sujeitos à competição interna. Talvez o aspecto mais promissor da sociologia dos mercados seja o potencial para teorizar, assim como examinar, empiricamente, as conexões entre dinâmicas intraorganizacionais e a competição e a troca interorganizacional.

Provavelmente, o mais estudado mecanis- 
mo de transmissão de estratégias e estruturas de uma firma para outra são as ligações entre os conselhos de administração das empresas (Mizruchi, 1996). Conselhos de gestão interligados influenciam a difusão de diferentes tipos de inovações estruturais e estratégicas (Burt, 1988; Davis, 1991; Gulati; Westphal, 1999; Rao; Sivakumar, 1999). Os sociólogos tendem a ver essas interligações como mecanismos de cooptação de vários tipos de dependência de recursos, na medida em que geram confiança, troca de informações, mediação da competição e formação de alianças políticas (aqui se pode fazer a ligação novamente com a economia política).

A estruturação social dos mercados se dá geralmente em resposta aos problemas da competição e da troca. A sociologia dos mercados não postula que tais problemas serão sempre resolvidos. No entanto, ela, de fato, pressupõe que, onde mercados estáveis emergem, tais estruturas vão aparecer na medida em que as firmas descobrem como resolver seus problemas. Ao estabelecer relações sociais não somente com competidores, mas também com clientes, fornecedores e empregados, as firmas podem estabelecer confiança e garantir acesso a recursos escassos. Ao responder às diretivas do governo e tentar cooptar as agências governamentais, as firmas também podem assegurar seu futuro. Todos esses mecanismos sociais fazem com que seja possível, para elas, lidar com suas dependências de recursos e sobreviver. Pode-se concluir que, a despeito da diversidade de perspectivas teóricas, linguagens e técnicas de análise de dados, a literatura empírica sobre sociologia dos mercados converge quanto a alguns dos principais mecanismos por meio dos quais a estruturação social dos mercados pode ser entendida. A maneira correta de pensar sobre tais mecanismos é que eles formam uma caixa de ferramentas que poderia plausivelmente ser usada para analisar um mercado particular. Um dos grandes perigos, na literatura, é que estudiosos frequentemente enfocam seu mecanismo favorito em detrimento de outras maneiras possíveis de enten- der o que está se passando no mercado em análise. Discutimos sobre como resolver esse problema ao final desta revisão.

\section{ARGUMENTOS DIVERGENTES}

As controvérsias reais, na sociologia dos mercados, são aquelas que não consistem no uso de diferentes termos para descrever conceitos similares, ou o fato de que estudiosos em algum grupo teórico ignorem as ideias de outros. Uma das mais importantes críticas das perspectivas gerais delineadas acima veio da escola de pensamento performativista. Os performativistas têm criticado o trabalho sociológico sobre mercados pelo fato de ele negligenciar a forma como os mercados são estruturados pela interação da atividade econômica com a descoberta científica e a criação de novas tecnologias. Dessa perspectiva, Callon (2002) argumentou que a sociologia dos mercados tem se preocupado demasiadamente em criticar a visão neoclássica de que os mercados consistem em trocas anônimas, encerradas em si mesmas, e não têm se preocupado suficientemente com o papel dos economistas (e outros) na criação de ferramentas culturais que realmente constituem os mercados em campos como as finanças (Guala, 2001; Knorr-Cetina; Bruegger, 2002; Mackenzie; Milo, 2003; Mackenzie, 2004, 2005). Para demonstrar esse argumento, os estudiosos têm se debruçado sobre a dialética entre as teorias financeiras e a implementação de novos produtos financeiros, assim como sobre a forma como o crescimento desses mercados reflete as formas como aquelas teorias são usadas e aplicadas.

Essa perspectiva introduz um tipo de dinamismo cultural nos processos de mercado e aumenta o papel da inovação tecnológica. Atores em mercados existentes inventam novos produtos de forma autorreferida, o que, por sua vez, funciona no sentido de transformar os mercados existentes. Aqui, pensamos que poderia ocorrer um diálogo frutífero. A despeito da afirma- 
ção de Callon (2002) em sentido contrário, os estudiosos, utilizando a ecologia populacional, a teoria institucional e a teoria de redes, têm se interessado pela ligação entre as novas formas culturais dos produtos e o desenvolvimento dos recursos das firmas (por exemplo, Caroll e Swandinathan, 2000; Granovetter e McGuire, 1998; Haveman e Rao, 1997; Lounsbury e Rao, 2004; Powell et al., 2005). Obviamente, boa parte dessa pesquisa tem dado mais ênfase a questões de legitimidade, dependência de recursos e confiança, algo por que Callon (2002) parece não se interessar. No entanto, dado que os estudiosos têm se interessado na coevolução de tecnologias industriais e formas organizacionais, o foco de Callon (2002) na maneira como os atores, ao criarem tecnologias, produzem novos mercados parece menos contraditório em relação aos modelos orientados para a produção e mais complementares a eles. Ligar o processo de descoberta e implementação de tecnologias em novos mercados aos problemas de dependência de recursos, competição, troca e legitimidade provavelmente será uma frutífera agenda de pesquisa.

Um dos aspectos subjacentes ao argumento de Callon (2002) é que novos mercados são, com frequência, fundados para cumprir um objetivo, porém acabam servindo a um objetivo totalmente diferente. Por exemplo, o telefone foi pensado para ser útil somente para se fazer negócios e, desde o início, as empresas telefônicas desencorajaram seu uso casual. (Fisher, 1994). No entanto, uma vez que os consumidores descobriram que esse seria um meio para manter contato entre si, as telefônicas foram forçadas a expandir seus serviços dramaticamente. Essas descobertas, de cunho mais acidental do uso da tecnologia, implicam menos agência e intenção e mais processos de descoberta sobre a serventia das coisas.

Uma segunda arena de discordância se refere ao fato de que os estudos se concentram nos produtores que competem entre si, ou nos fornecedores e consumidores. Muitos estudos, na sociologia dos mercados, enfocam comunidades de produtores. Tais estudos, focados em produtores, com frequência apresentam os consumidores apenas até o ponto em que as maquinações das firmas eventualmente produzem uma estrutura social que seja eficaz em mitigar a competição ou reduzir a dependência de recursos das firmas competidoras (Zelizer, 2005 para uma versão mais extensa dessa crítica). Quando os estudiosos enfocam os fornecedores e compradores, sua discussão enfoca diferentes relações. Com mais frequência, essas relações são vistas como indexadas à confiança por meio de laços de rede diretos, que refletem relações sociais existentes entre compradores e vendedores (Baker; Faulkner; Fisher, 1998; Uzzi, 1996, 1997).

Nenhuma dessas perspectivas captura o que se dá nos grandes mercados consumidores, nos quais os compradores são indivíduos, e suas preferências são expressas de formas menos diretas. Estudiosos mais interessados na construção social dos produtos têm criticado o foco da sociologia dos mercados na produção. Até certo ponto, o uso dos produtos para se fazer julgamentos morais ou reclamar status social pode ser analiticamente separado do problema de produzir um mercado de produto estável. Ao fim e ao cabo, a forma como os automóveis são usados e o que eles significam para seus usuários e para os outros pode não fazer diferença em relação às firmas que sobreviverão nas posições mais altas ou baixas do mercado, ou quantas firmas existem e como elas são organizadas. Ainda assim, essa disjunção entre produtores e consumidores é uma das fronteiras interessantes na sociologia dos mercados.

Zelizer $(1983,1994,1997)$ argumenta que o foco na produção perde de vista o fato de que os consumidores têm de ser convencidos sobre o valor e a legitimidade dos produtos. Ela argumenta que inúmeras questões morais emergem na criação de novos mercados. A indústria de seguros de vida, por exemplo, teve de superar a ambiguidade moral óbvia de as pessoas comprarem seguros que atribuem um preço às suas mortes. Além do mais, as firmas foram colocadas na posição de fazer apostas na morte de ou- 
tras pessoas. Muitas pessoas resistiram a comprar seguros de vida devido a essas qualidades macabras. Somente quando os consumidores foram convencidos, por meio do marketing, de que o seguro de vida era uma maneira de oferecer segurança para os entes queridos após a morte é que o mercado decolou. Uma sociologia dos mercados focada na produção não é capaz de levar em consideração os consumidores e o marketing e, ao não fazê-lo, perde um aspecto importante da origem dos mercados.

A indústria de seguros de vida apresenta um quebra-cabeça empírico que permite aos estudiosos explorar o papel relativo de consumidores, governos e firmas na produção de um novo produto. Os problemas da indústria não eram apenas o de convencer as pessoas a comprarem seguros. No início do mercado, as firmas frequentemente vendiam apólices a preços demasiadamente baixos, para ter retorno. Quando as pessoas solicitavam suas indenizações, muitas das pequenas firmas faliam e seus proprietários desapareciam. Eventualmente, a regulação governamental se tornou mais extensa para proteger os consumidores. Essas intervenções parecem ter sido tão importantes para a geração de confiança (entre firmas e consumidores) quanto o problema da moralidade do mercado (Heimer, 1985).

Um diálogo frutífero é necessário entre aqueles favoráveis a uma abordagem mais cultural para os consumidores, que enfoque os usos morais e sociais dos produtos e aqueles favoráveis uma abordagem que dê mais ênfase à solução dos problemas da competição entre os produtores. Esse diálogo permitiria que nós entendêssemos se essas visões são contraditórias ou complementares. Considerar todos os lados do problema nos ajudaria a obter um quadro mais claro quanto à maneira como se relacionam a produção e a legitimação de novos produtos e a estruturação de mercados estáveis.

A questão sobre a dinâmica dos mercados conduz a um desacordo mais geral na literatura em torno da estabilidade e da mudança. As abordagens da ecologia populacional, da teoria institucional e algumas versões da teoria de redes (i. e., White) têm um argumento explícito de que processos projetos de abertura de mercados serão muito diferentes de processos de estabilização de mercados. Para a ecologia populacional, a desvantagem dos novos e pequenos é particularmente aguda na formação de novos mercados. Nesses momentos, ou as firmas não sabem quais são suas principais dependências de recursos, ou não são capazes de entregar, de modo confiável, os produtos que as pessoas desejam. Assim, elas são mais vulneráveis à competição. Uma vez que os mercados tenham se estabilizado, as firmas existentes podem permanecer incumbentes estáveis por longos períodos. Tais firmas enfrentam desafios constantemente, porém esses momentos são qualitativamente diferentes dos momentos de formação de mercados. A teoria institucional (Fligstein, 1996) também postula que produzir um mercado como campo é um projeto social e político que começa sem relações estáveis. O argumento básico de White é que, se as firmas não podem encontrar uma estrutura de papéis reprodutível, mercados estáveis não irão emergir, e elas irão à falência.

Há muitos pontos de vista diferentes para esses processos. Inspirados pela visão de Nelson e Winter (1982), da ecologia populacional, muitos estudiosos argumentaram que algumas indústrias estão em constante estado de fluxo. As firmas devem ser ágeis, mudar suas tecnologias e inovar ou correr o risco de desaparecer (Powell et al., 2005; Stark;Vedrez, 2006). A perspectiva da performatividade também parece ser compatível com essa visão.

Para resolver tais argumentos, os estudiosos precisam ter mais clareza sobre como eles poderiam medir e interpretar a estabilidade ou o equilíbrio. Colocado de outra forma, quando uma mudança no mercado é uma mudança? A visão geral de um mercado como nicho, papel, status ou estrutura hierárquica de incumbentes e desafiadores implica que uma mudança no mercado envolveria uma mudança nas identidades e posições dos principais atores. Isso envol- 
veria uma mudança na definição subjacente do mercado (isto é, suas principais atividades, formas de organização etc.). Porém essa definição de mudança tem diversos problemas. Em primeiro lugar, alterações nas identidades tanto das firmas desafiadoras, quanto das incumbentes, ocorrem o tempo todo. Não seria o caso de argumentar que quaisquer destas mudanças desinstitucionalizaria o mercado. Em segundo lugar, mudanças nos produtos e na produção também evoluem com o tempo (frequentemente de modo incremental). Aqui, novamente, é o caso de se questionar até que ponto tais mudanças representam transformações subjacentes aos mercados existentes. Muitas das discordâncias sobre a estabilidade e a mudança, na literatura, repousam sobre a maneira como se pensa sobre o que é exatamente uma mudança.

Finalmente, um dos problemas que assombra todas as discussões na sociologia dos mercados é o problema da eficiência. A ideia econômica de eficiência é que recursos escassos são alocados de modo a maximizar seu retorno. A teoria econômica neoclássica assume que a única maneira de tal alocação poder ocorrer é que o mercado esteja em equilíbrio e que a atualização constante da informação significa que as firmas estão sempre alterando suas atividades para manter a eficiência. A sociologia do mercado tem uma relação ambígua com essa assertiva, a qual varia entre principalmente aceitar a lógica econômica e basicamente rejeitá-la. Então, por exemplo, na visão da ecologia populacional, as dependências de recursos das organizações determinam que aquelas que não se adaptem a seus nichos irão perecer. Hannan e Freeman (1977), claro, constroem um argumento geral sobre todas as formas de organização. Eles assumem que qualquer que seja a dependência de recursos que caracterize o nicho (e aqui eles incluem organizações sem fins lucrativos e o Estado), ela irá operar para selecionar os vencedores e perdedores. Se o nicho é um mercado, então se pode inferir que dificilmente se pode separar o argumento da ecologia populacional da visão pro- posta por Friedman (1957), a qual sugere que as forças de mercado determinam a eficiência e, portanto, os vencedores e perdedores. O que separa a ecologia populacional da economia é que o mecanismo de preço é apenas uma fonte potencial de dependência de recursos.

Muitos dos nossos estudos sobre a estrutura social dos mercados terminam argumentando que as relações sociais subjacentes aos mercados têm efeitos eficientes. Se as firmas têm as conexões sociais certas, elas podem resolver seus problemas de dependência de recursos e se reproduzir (Baker; Faulkner; Fisher, 1998; Stuart; Hoang; Hybels, 1999; Stuart; Sorenson, 2003; Uzzi, 1997). Alguns autores, no entanto, também reconhecem que, enquanto as relações sociais poderiam produzir resultados estáveis para os participantes, elas, de fato, poderiam também comprometer a eficiência do mercado (Podolny, 2001). Relações sociais de longo prazo não apenas produzem confiança, mas também permitem que surjam cartéis e combinação de preços, o que, em alguns casos, torna as firmas mais vulneráveis, porque seus fornecedores podem tirar vantagem delas, cobrando preços mais altos. Granovetter (1985, 1994) é ambíguo em relação a essa questão, às vezes parecendo ver as redes sociais como forma de as pessoas resolverem seus problemas de confiança e, portanto, produzir resultados eficientes, e, em outros momentos, vendo tais redes como possíveis mecanismos para extração de renda (e até mesmo comportamentos ilegais). Em sua revisão de literatura mais recente sobre grupos empresariais, por exemplo, ele parece retratar esses grupos como geradores de eficiência.

A literatura em economia política também tem apresentado essa ambivalência. Os estudiosos que têm documentado a existência de diferentes sistemas nacionais de capitalismo oscilam entre uma visão protecionista e uma visão eficiente daqueles sistemas. Assim, por exemplo, uma série de livros tem partido da premissa de que as diferenças entre sistemas nacionais de capitalismo estão em vias de desaparecer porque a difusão do capitalismo global está forçan- 
do as firmas a selecionarem as formas mais eficientes de organização (Berger; Dore, 1996). Pressupõe-se que os vários modelos nacionais devem estar escondendo ineficiências que protegem os trabalhadores, e que o mundo do mercado simplesmente forçará tais modelos a uma mudança. Em seguida, esses livros mostram que, na verdade, os capitalismos do Japão, da Coreia, da Alemanha e da França parecem ser resilientes. Eles frequentemente concluem que cada um desses modelos nacionais deve ser eficiente de alguma maneira e que, face à competição internacional, as firmas se adaptam às novas circunstâncias sem mudar por completo sua maneira de funcionar. Hall e Soskice (2001) argumentam que o sistema nacional tem de ter algumas propriedades eficientes, assim como a habilidade para se adaptar a mudanças vindas de fora. O debate sobre o papel dos Estados, da lei e da luta de classes nos projetos de desenvolvimento sugere como é difícil entender a eficiência do mercado.

Alguns estudiosos são ainda mais céticos sobre a eficiência das relações sociais. Fligstein (1990) vê a emergência da grande corporação nos Estados Unidos, na virada para o século XX, como sendo, principalmente, uma função da tentativa de controlar a competição dentro de indústrias particulares, negando, dessa forma, as interpretações de Chandler Junior (1977) e Williamson (1985) sobre a eficiência. Dobbin (1994) vê as diferenças nas maneiras por meio das quais as relações entre Estado e empresas moldaram as indústrias de transporte ferroviário como reflexo de diferenças na cultura e na política, mais do que diferenças na eficiência. A literatura sobre capitalismos comparados frequentemente demonstra que os principais fatores que influenciam a organização das firmas, em um estado-nação, concernem à história, cultura, luta de classes e ao papel do Estado (Roe, 2003).

Uma interpretação oriunda tanto da teoria organizacional quanto da teoria institucional consiste em preocupar-se menos com a eficiência e mais com a eficácia organizacional. A teoria organizacional se deu conta, há muito tempo, de que a sobrevivência das organizações poderia vir de diferentes lugares (Thompson, 1967): explorar ambientes ricos em recursos, defender-se de competidores ou cooptar suas dependências de recursos. Assim, resolver o problema da luta de classes, obter financiamento e conseguir intervenção estatal para garantir soluções para a competição predatória são todas elas táticas que deveríamos esperar que as firmas utilizassem para sobreviver. A alocação eficiente dos recursos internos, desse ponto de vista, é apenas uma dessas táticas.

O problema dessa perspectiva (ainda que aprimore nossa visão sobre o comportamento relevante da firma!) é que sabemos que os mercados surgem e desaparecem, vêm e vão, e que as firmas que existem hoje podem desaparecer amanhã. Os sociólogos não querem dizer que as firmas, nos mercados, não se preocupam com preços, custos e satisfação dos clientes, importandose apenas com o controle de suas dependências de recursos ou com a obtenção de intervenção estatal para proteger suas fatias de mercado. Uma maneira de sair desse dilema é perceber que, às vezes, as estruturas sociais podem promover eficiências e, outras vezes, elas podem proteger os incumbentes. Um dos objetivos da sociologia econômica deveria ser usar nossas ferramentas para entender a maneira como isso funciona em mercados particulares. Tal perspectiva é cara aos objetivos da velha economia industrial, a qual buscava uma maneira de identificar quando as estruturas de mercado eram resultantes de processos eficientes ou tentativas de controlar mercados.

A competição em novos mercados tende a ser diferente da competição em mercados estáveis. As firmas, nos dois casos, tentarão fazer o que estiver ao seu alcance para sobreviver. Em mercados novos, as firmas têm muitas dependências de recursos que fazem com que sua sobrevivência seja difícil. Ainda assim, elas podem usar suas relações sociais com entidades corporativas maiores, fornecedores, clientes e governos para construir coalizões que possam produzir estabilidade. As relações com os competidores podem evoluir à medida que as firmas visualizam a parte do mercado em que elas que- 
rem estar e à medida que os segmentos do mercado são definidos. Em mercados estáveis, os incumbentes têm mais ferramentas para derrotar os competidores, seja por meio de competição via preço, seja usando várias ferramentas para resistir à entrada dos competidores no mercado, ou cooptando os competidores copiando-os ou comprando-os. Os mercados estão sempre em ascensão e queda, o que quer dizer que tentativas de controlá-los estão sempre potencialmente em risco. Assim, por exemplo, a indústria automobilística dos Estados Unidos permaneceu estável aproximadamente de meados da década de 1930 até os anos 1970 (talvez até os anos 1990). Os principais participantes norte-americanos naquele mercado são firmas que agora estão se aproximando dos cem anos de existência. No entanto, desafios a essa indústria existem hoje, e nada garante que os principais produtores norte-americanos sobreviverão ou se manterão como corporações separadas.

\section{CONCLUSÃO}

A sociologia dos mercados tornou-se um campo de estudos maduro. Os estudiosos desenvolveram um conjunto de conceitos para descrever e entender como as relações sociais estruturam todas as formas de mercados. Junto das diversas perguntas fascinantes que estão para ser exploradas, ainda existe uma cacofonia de vozes esposando diferentes estratégias e perspectivas, com a qual se podem explorar aquelas questões. Argumentamos que, de muitas maneiras, os estudiosos falaram sem levar em consideração os demais, e que isso se deu em detrimento do crescimento focado do campo. Há muitos pontos de concordância na sociologia dos mercados e tentamos explicitá-los.

Se as pessoas estiverem convencidas de nossos argumentos, isso implica duas prescrições para a pesquisa subsequente. Os estudiosos deveriam levantar e explorar as diferenças na terminologia entre suas perspectivas e as demais, para decidir a relevância dessas diferenças para a compreensão dos casos empíricos. Os estudiosos também deveriam estar abertos à possibilidade de os mecanismos que outros estudiosos propõem serem relevantes para seus casos particulares. Um caso exemplar desse tipo de pesquisa é o recente livro de Mackenzie (2005), no qual ele cuidadosamente analisa o papel da política, dos mercados, das instituições e da economia no sentido de entender a emergência dos mercados financeiros modernos. Isso não significa que todos os mecanismos operam em todos os casos. No entanto, esse tipo de consideração cuidadosa provavelmente conduzirá a um melhor entendimento do escopo das perspectivas de vários autores. Se os estudiosos se engajarem nesse tipo de discussão honesta, o campo também provavelmente entenderá melhor quais são suas verdadeiras discordâncias e progredir em outras questões. Esperamos que nossa revisão ajude a contribuir para o fermento intelectual e encoraje a continuação da pesquisa e do debate.

Recebido para publicação em 20 de dezembro de 2011 Aceito em 08 de fevereiro de 2012

\section{REFERÊNCIAS}

AHMADJIAN, Christina; ROBINSON, Patricia. Safety in numbers: downsizing and the deinstitutionalization of permanent employment in Japan. Administrative science quarterly, v. 46, n. 4, p. 622-654, dez., 2001.

ALBERT, Michael. Capitalism against capitalism. Londres: Wiley, 1993.

AMSDEN, Alice. Diffusion of development: the lateindustrializing model and greater East Asia. The american economic review, v. 81, n. 2, p. 282-286, maio, 1991.

AOKI, Masahiko. Information, incentives and bargaining in the Japanese economy: a microtheory of the Japanese Economy. Cambridge: Cambridge University Press, 1990.

BAKER, Wayne. The social structure of a national securities market. American journal of sociology, v. 89, n. 4, p. 775811, jan., 1984.Disponível em: http:// webuser.bus.umich.edu/wayneb/pdfs/sociology/ Social\%20Struct.\%20Nat.\%20Sec.\%20Market.pdf . Acesso em: 25 jan. 2013.

; FAULKNER, Robert; FISHER, Gene. Hazards of the market: the continuity and dissolution of interorganizational market relationships. American sociological review, v. 63, n. 2, p. 147-177, abr., 1998. Disponível em: http:// webuser.bus.umich.edu/wayneb/pdfs/interorg/ 
Hazards\%20of\%20the\%20Market.pdf . Acesso em: 25 jan. 2013.

BARON, James; BIELBY, William. Bringing the firms back in: stratification, segmentation, and the organization of work American sociological review, v. 45, n. 5, p. 737-765, out., 1980

; HANNAN, Michael; BURTON, Diane. Building the iron cage: determinants of managerial intensity in the early years of organizations. American sociological review, v. 64 n. 4, p. 527-547, ago., 1999. Disponível em: http:// burton.scripts.mit.edu/docs/IronCage.pdf . Acesso em: 25 jan. 2013.

BECKMAN, Christine; HAUNSCHILD, Pamela. Network learning: the effects of partners' heterogeneity of experience on corporate acquisitions. Administrative science quarterly, v. 47, n. 1, p. 92-124, mar., 2002.

BERGER, Suzanne; DORE, Philippe (Ed.). National diversity and global capitalism. Ithaca: Cornell University Press, 1996.

BENUZA, Danie; STARK, David. Tools of the trade: the socio-technology of arbitrage in a Wall Street trading room. Industrial and corporate change, v. 13, n. 2, p. 369-400, abr., 2004. Disponível em: www.santafe.edu/media/ workingpapers/04-02-003.pdf. Acesso em: 24 jan. 2013.

BIGGART, Nicole; BEAMISH, Thomas. The economic sociology of conventions: habit, custom, practice, and routine in market order. Annual Review of Sociology, Palo Alto, v. 29, p. 443-464, ago., 2003.

BLAU, Peter; DUNCAN, Otis. The american occupational structure. New York: Wiley, 1967.

BLOCK, F; EVANS, P. The state and the economy. In: SMELSER, Neil; SWEDBERG, Richard (Org.). The handbook of economic sociology. New York: Princeton University Press, 2005. p. 505-526.

BOURDIEU, Pierre; NICE, Richard. Distinction: a social critique of the judgment of taste. Cambridge: Harvard University Press, 1984.

Principles of an economic anthropology. In: SMELSER, Neil; SWEDBERG, Richard (Org.). The handbook of economic sociology. New York: Princeton University Press, 2005. p. 75-89.

BOYER, Robert; DRACHE, Daniel (Ed.). States agains markets: the limits of globalization. Londres: Routledge, 1996

BURT, Ronald. Cooptive corporate actor networks: a reconsideration of interlocking directorates involving F American manufacturing? Administrative science quarterly, v. 25, n. 4, p. 557-582, dez., 1980. The stability of american markets. American journal of sociology, v. 94, n. 2, p. 356-395, set., 1988. Disponíve em: http://faculty.chicagobooth.edu/ronald.burt/research/files/88AJS.pdf. Acesso em: 25 jan. 2013.

Structural holes: the social structure of competition. Cambridge: Harvard University Press, 1992.

CALLON, Michel. The embeddedness of economic markets in economics. In: . (Org.). The laws of the market. Oxford: Blackwell, 1998. p. 1-57.

. Technology, politics and the market: an interview with Michel Callon. Economy and Society, v. 31, n. 2, p 285-306, 2002.

; MUNIESA, Fabian. Economic markets as calculative collective devices. Organizational studies, v. 26 , n. 8, p. 1229-1250, 2005. Disponível em www.coi.columbia.edu/pdf/callon-muniesa.pdf. Acesso em: 25 jan. 2013.

CAMPBELL, John; LINDBERG, Leon. Property rights and the organizational activity of the state. American sociological review, v. 55, n. 5, p. 3-14, out., 1990.
; HOLLINGSWORTH, Rogers; LINDBERG, Leon (Ed.). Governance of the american economy. Cambridge: New York: Cambridge University Press, 1991.

CARROLL, Glenn. Concentration and specialization: dynamics of niche width in populations of organizations. American journal of sociology, v. 90, n. 6, p. 1262-1283, maio, 1985.

; SWAMINATHAN, Anand. Why the microbrewery movement? Organizational dynamics of resource partitioning in the U.S. brewing industry. American journal of sociology, v. 106, n. 3, p. 715-62, 2000

CARRUTHERS, Bruce; ARIOVICH, Laura. The sociology of property rights. Annual Review of Sociology, Palo Alto, v. 30, p. 23-46, ago., 2004.

; HALLIDAY, Terence. Rescuing business and the making of corporate bankruptcy lawin England and the United State. Oxford: Oxford University Press, 1998.

CHANDLER JUNIOR, Alfred. Strategy and structure: chapters in the history of the industrial enterprise. Cambridge: MIT Press, 1962.

The visible hand: the managerial revolution in american business. Cambridge: Belknap, 1977.

CHESHIRE, Coye; COOK, Karen. The emergence of trust networks under uncertainty: implications for Internet interaction. Analyse \& Kritik, n. 28, p. 1-20, 2004. Disponível em: http://people.ischool.berkeley.edu/ coye/papers/ Cheshire-Cook.pdf. Acesso em: 25 jan. 2013.

CSIKSZENTMIHALYI, Mihaly; ROCHBERG-HALTON, Eugene. The meaning of things: domestic symbols and the self. Cambridge: Cambridge University Press, 1981.

DAVIS, Gerald. Agents without principles? The spread of the poison pill through the intercorporate network. Administrative science quarterly, v. 36, n. 4, p. 583-613, dez., 1991. Disponível em: http://webuser.bus.umich.edu/gfdavis/ Papers/Agents\%20without\%20principles.pdf. Acesso em: 25 jan. 2013.

; DIEKMANN, Kristina; TINSLEY, Catherine. The decline and fall of the conglomerate firm in the 1980s: the deinstitutionalization of an organizational form. American sociological review, v. 59, n. 4, p. 547-570, ago., 1994. Disponível em: http://webuser.bus.umich.edu/gfdavis/papers/ decline\%20and\%20fall.pdf. Acesso em: 25 jan. 2013.

DELANEY, Kevin. Strategic bankruptcy: how corporations and creditors use chapter 11 to their advantage. Berkeley: University of California Press, 1992.

DIMAGGIO, Paul; POWELL, Walter. The iron cage revisited: institutional isomorphism and collective rationality in organizational ûelds. American sociological review, v. 48 n. 2, p. 147-160, abr., 1983. Disponível em: http:// www.ics.uci.edu/ corps/phaseii/DiMaggioPowellIronCageRevisited-ASR.pdf. Acesso em: 25 jan. 2013.

DOBBIN, Frank. Forging industrial policy: the United States, Britain, and France in the railway age. Cambridge: Cambridge University Press, 1994.

DOWD, Timothy. The market that antitrust built: public policy, private coercion, and railroad acquisitions, 1825 to 1922 . American Sociological Review, v. 65, n. 5, p. 631-657, out., 2000.

DORE, Ronald. British factory - japanese factory: the origins of national diversity in industrial relations. Londres: Allen \& Unwin, 1973.

. Taking Japan seriously: a Confucian perspective on leading economic issues. Stanford: Stanford University Press, 1987.

The distinctiveness of Japan. In: CROUCH, Colin; STREECK, Wolfgang (Org.). The political economy of modern 
capitalism: mapping convergence and diversity. Londres: Sage, 1997. p. 19-32.

DURKHEIM, Émile. The division of labor in society. New York: Free Press, 1964.

EISENSTADT, Shumuel. Tradition, change, and modernity. New York: Wiley, 1973.

EMERSON, Richard. Power-dependence relations. American sociological review, v. 27, n. 1, p. 31-41, fev., 1962. Disponível em: www.rci.rutgers.edu/ pmclean/emerson\% 20article.pdf. Acesso em: 25 jan. 2013.

EVANS, Peter. Embedded autonomy: states and industria transformation. Princeton: Princeton University Press, 1995.

FAMA, Eugene; JENSEN, Michel. Separation of ownership and control. Journal of law and economics, v. 26, p. 301325, jun., 1983.Disponível em: http://papers.ssrn.com/sol3/ papers.cfm?abstract_id=94034. Acesso em: 25 jan. 213.

FISHER, Claude. America calling: a social history of the telephone to 1940. Berkeley: University of California Press, 1994.

FISS, Pete; ZAJAC, Edward. The diffusion of ideas over contested terrain: the (non)adoption of a shareholder value orientation among German ûrms. Administrative science quarterly, v. 49, n. 4, p. 501-534, dez., 2004.

FLIGSTEIN, Niel. The spread of the multidivisional form among large firms, 1919-1979. American Sociological Review, v. 50, n. 3, p. 377-391, jun., 1985.

. The transformation of corporate control. Cambridge: Harvard University Press, 1990.

. The structural transformation of American industry: an institutional account of the causes of diversiûcation in the largest ûrms. In: POWELL, Walter; DIMAGGIO, Paul (Org.). The new institutionalism in organizational analysis Chicago: University of Chicago Press, 1991. p. 311-336.

Markets as politics: a political cultural approach to market institutions. American sociological review, v. 61, n. 4, p. 656-673, ago., 1996.

The architecture of markets: an economic sociology of twenty-first-century capitalist societies. Princeton: Princeton University Press, 2002.

; CHOO, Jennifer. Law and corporate governance.

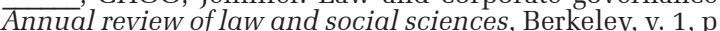
64-84, dez., 2005.Disponível em: <http:// www.irle.berkeley.edu/workingpapers/114-05.pdf > . Acesso em: 25 jan. 2013.

FOURCADE-GOURINCHAS, M. Theories of markets and theories of society. American behavioral scientist, v. 50, n. 8, abr., 2007.

FRIEDMAN, Milton. A theory of the consumption function. Princeton: Princeton University Press, 1957.

GRANOVETTER, Mark. Getting a Job: a study of contacts and careers. Cambridge: Harvard University Press, 1974.

Economic action and social structure: the problem of embeddedness. American journal of sociology, v. 91, n . 3, p. 481-510, nov., 1985. Disponível em: http:// glennschool.osu.edu/faculty/brown/home/org\%20theory/ readings/granovetter1985.pdf. Acesso em: 25 jan. 2013.

Business groups. In: SMELSER, Niel; SWEDBERG, Richard (Org.). The handbook of economic sociology. New York: Princeton University Press, 1994. p. 453-475.

. The impact of social structure on economic outcomes. Journal of economic perspectives, v. 19, n. 1, p. 33-50, 2005. Disponível em: http://sociology.stanford.edu/people/ mgranovetter/documents/granimpacteconoutcomes 000.pdf. Acesso em: 25 jan. 2013.

; MCGUIRE, P. The making of an industry: electricity in the U.S. In: CALLON, Michel (Org.). The laws of the market. Oxford: Blackwell, 1998. p. 147-173.

GUALA, Francesco. Building economic machines: the FCC auctions. Studies in history and philosophy of science, v. 32 n. 3, p. 453-477, 2001. Disponível em: http://users.unimi.it/ guala/FCC_FINAL.pdf. Acesso em: 25 jan. 2013.

GULATI, Ranjay, WESTPHAL, James. Cooperative or controlling? the effects of CEO-board relations and the content of interlocks on the formation of joint ventures. Administrative science quarterly, v. 44, n. 3, p. 473-506, set. 1999. Disponível em: http://webuser.bus.umich.edu/westjd/ Articles/Cooperative_or_Controlling.pdf. Acesso em: 25 jan. 2013.

HALL, Peter; SOSKICE, David (Ed.). Varieties of capitalism: the institutional foundations of comparative advantage. Oxford: Oxford University Press, 2001. Disponível em: http:/ /digamo.free.fr/hallsosk.pdf. Acesso em: 25 jan. 2013.

HANNAN, Michel; FREEMAN, John. The population ecology of organizations. American journal of sociology, v. 82, n. 5, p. 929-964, mar., 1977. Disponível em: https:// www 2.bc.edu/candace-jones/mb $851 /$ A pr 9/ HannanFreeman_AJS_1977.pdf. Acesso em: 25 jan. 2013.

The ecology of organizational founding: American labor unions, 1836-1985. American journal of sociology, v. 92, n. 4, p. 910-943, jan., 1987.

Density dependence in the growth of organizational populations. In: CARROLL, Glenn (Org.). Ecological models of organization. Cambridge: Ballinger, 1988. p. 7-32.

HAUNSCHILD, Pamela. Interorganizational imitation: the impact of interlocks on corporate acquisition activity. Administrative science quarterly, v. 38, n. 4, p. 564-592, dez., 1993.

HAUSER, Robert; FEATHERMAN, David. The process of stratiûcation: trends and analysis. New York: Academic Press, 1977.

HAVEMAN, Heather; RAO, Hayagreeva. Structuring a theory of moral sentiments: institutional and organizational coevolution in the early thrift industry. American journal of sociology, v. 102, n. 6, p. 1606-1651, maio, 1997.

HEIMER, Carol. Reactive risk and rational action: managing moral hazard in insurance contracts. Berkeley: University of California Press, 1985.

HIRSCH, Paul. From ambushes to golden parachutes: corporate takeovers as an instance of cultural framing and institutional integration. American journal of sociology, v. 91, n. 4, p. 800-837, jan., 1986.

HODSON, Randy. Workers earnings and corporate economic structure. New York: Academic Press, 1983.

HOLLINGSWORTH, J. Rogers. (Org.). Governing capitalist economies: performance and control of economic sectors. New York: Oxford University Press, 1994.

INGRAM Paul; RAO Hayagreeva. Store wars: the enactment and repeal of anti-chain-store legislation in America. American journal of sociology, v. 110, n. 2, p. 446-486, set. 2004.Disponível em: www.columbia.edu/ pi17/ ingram_rao.pdf. Acesso em: 26 jan. 2013.

; ROBINSON, Jeffrey; BUSCH, Marc. The intergovernmental network of world trade: IGO connectedness, governance, and embeddedness. American journal of sociology, v. 111, n. 3, p. 824-858, nov., 2005. Disponível em: http://www9.georgetown.edu/faculty/mlb66/ ingram_igos.pdf. Acesso em: 26 de jan. 2013.

JACOBS, Jerry A. ASR's greatest hits. American sociological review, v. 70, p. 1-3, fev., 2005. Disponível em: http://sociology.sas.upenn.edu/sites sociology.sas.upenn.edu/files/asr_greatest_\%20hits.pdf. Acesso em: 26 de jan. 2013.

JOHNSON, Chalmers. MITI and the japanese miracle: the 
growth of industrial policy, 1925-1975. Palo Alto: Stanford University Press, 1982.

KALLEBERG, Arne; GRIFFIN, Larry. Class, occupation, and inequality in job rewards. American journal of sociology, v. 85, n. 4, p. 731-768, jan., 1980.

KERR, Charles; DUNLOP, John; HARBISON, Frederick Industrialism and industrial man: the problems of labor and management in economic growth. Cambridge: Harvard University Press, 1960.

KOLLOCK, Peter. The emergence of exchange structures: an experimental study of uncertainty commitment, and trust. American journal of sociology, v. 100, n. 2, p. 313-345, set., 1994.

The production of trust in online markets. In: LAWLOR, Edward; THEYE, S. (Org.). Advances in group processes. New York: Elsevier, 1999. p. 99-123.

KNORR-CETINA, Karin; BRUEGGER, Urs, Globa microstructures: the virtual societies of ûnancial markets. American journal of sociology, v. 107, n. 4, p. 905-950, jan. 2002. Disponível em: http://ceas.iscte.pt/ethnografeast/ Karin\%2520Knorr-Cetina/Global\%2520Microstructures\% 2520AJS\%2520PDF\%2520publ\%2520version.pdf. Acesso em: 26 jan. 2013

KRIPPNER, Greta. The elusive market: embeddedness and the paradigm of economic sociology. Theory and society, $\mathrm{v}$ 30, n. 6, p. 775-810, dez., 2002.

LEIFER, E.; WHITE, H. A structural approach to markets In: MARK, S. Mizruchi; SCHWARTZ, Michel (Org.). Intercorporate relations: Structural analysis of business Cambridge: Cambridge University Press, 1987. p. 85-108.

LERNER, Daniel The passing of traditional society: modernizing the middle east. Glencoe: Free Press, 1963.

LIE, John. Sociology of markets. Annual review of sociology, v. 23, p. 341-360, 1997.Disponível em: http:/userpage.fuberlin.de/ diazbone/markt/Lie.pdf. Acesso em: 26 jan. 2013.

LINCOLN, James; GERLACH, Michael; AHMADJIAN, Christina. Keiretsu networks and corporate performance in Japan. American sociological review, v. 61, n. 1, p. 67-88, fev., 1996.

LOUNSBURY, Michael; RAO, Hayagreeva. Sources of durability and change in market classiûcations: a study of reconstitution of product categories in the American mutual fund industry, 1994-1985. Social forces, v. 82, n. 3, p. 969-999, mar., 2004 Disponível em: http://apps.business.ualberta.ca/mlounsbury/ papers/rao.pdf. Acesso em: 26 jan. 2103 market: portfolio insurance, the 1987 crash and the performativity of economics. Economy and society, v. 33, n. 3, p. 303-334, ago., 2004.

; MILO, Yuval. Constructing a market, performing . A camera, not a machine. Cambridge: MIT Press, exchange. American journal of sociology, v. 109, n. 1, p. 107-145, jul., 2003.

- MARCH, J., SIMON, H., GUETZKOW, H. Organizations New York: Wiley, 1958.

MILES, Robert. Macro organizational behavior. Santa Monica: Goodyear, 1980

MILES, Raymond E.; SNOW, Charles. Organizational strategy, structure, and process. New York: McGrawHill, 1978.

MIZRUCHI, Mark. What do interlocks do? An analysis critique and assessment of research on interlocking directorates. Annual review of sociology, Palo Alto, v. 22, p. 271-298 ago., 1996
NELSON, Richard; WINTER, Sidney. An evolutionary theory of economic change. Cambridge: Harvard University Press, 1982.

OCASIO, William; KIM, Hyosun. The circulation of corporate control: selection of functional backgrounds of new CEOs in large U.S. manufacturing ûrms, 1981-1992. Administrative science quarterly, v. 44, n. 3, p. 532-562, set., 1999

PFEFFER, Jeffrey. Power in organizations. Marshûeld: Pitman, 1981.

; SALANCIK, Gerrald. The external control of organizations: a resource dependence perspective. New York: Harper \& Row, 1978.

PODOLNY, Joel. A status-based model of market competition. American journal of sociology, v. 98, n. 4, p. 829-872, jan., 1993.

Networks as the pipes and prisms of the market. American journal of sociology, v. 107, n. 1, p. 33-60, jul. 2001.Disponível em: http://lms.hse.ru/content/lessons/599/ podolny\%20networks\%20ajs\%202001.pdf. Acesso em: 26 jan. 2013.

POLANYI, Karl. The great transformation. Boston: Beacon, 1957.

POWELL,Walter; DIMAGGIO, Paul (Org.). The new institutionalism in organizational analysis. Chicago: University of Chicago Press, 1991.

et al. Network dynamics and ûeld evolution: the growth of interorganizational collaboration in the life sciences. American journal of sociology, v. 110, n. 4, p. 11321205, jan., 2005. Disponível em: www-personal.umich.edu/ $\sim$ jdos/pdfs/AJS.pdf. Acesso em: 26 jan. 2013.

RANGER-MOORE, James; BANASZAK-HOLL, Jane; HANNAN, Michel. Density-dependent dynamics in regulated industries: founding rates of banks and life insurance companies. Administrative science quarterly, v. 36, n. 1, p. 36-65, mar., 1991.

RAO, Hayagreeva; SIVAKUMAR, Kumar. Institutiona sources of boundary spanning structures: the establishment of investor relations departments in the Fortune 500 industrials. Organization science, v. 10, n. 1, p. 27-42, jan./ fev., 1999

ROE, Mark. Political determinants of corporate governance: political context, corporate impact. Oxford: Oxford University Press, 2003.

ROSTOW, W. The stages of economic growth: a noncommunist manifesto. Cambridge: Cambridge University Press, 1961.

SCHNEIBERG, Marc; SOULE, Sara. Institutionalization as a contested multilevel process: the case of rate regulation in American ûre insurance. In: DAVIS, Gerald et al. (Org.). Social movements and organization theory. Cambridge: Cambridge University Press, 2005. p. 122-161.

SCOTT, W. Richard; MEYER, John. The organization of institutional sectors. Stanford: Stanford University, 1982.

SHEPARD, Ronald. Theory of cost and production functions Princeton: Princeton University Press, 1970.

SIMON, Herbert. Models of man: social and rational; mathematical essays on rational human behavior in a social setting. New York: Wiley, 1957.

SLATER, Don. Consumer culture and modernity. Cambridge: Blackwell, 1997.

SMELSER, Neil; SWEDBERG, Richard (Org.). The handbook of economic sociology. 2. ed. New York: Princeton University Press, 2005.

(Org.). The handbook of economic sociology. New York: Princeton University Press, 1994. 
SPENCE, A. Michel. Market signaling: informational transfer in hiring and related screening processes. Cambridge: Harvard University Press, 1974.

STARK, David; VEDREZ, B. Social times of network spaces: network sequences and foreign investment in Hungary. American journal of sociology, v. 111, n. 5, p. 1367-1411, mar., 2006. Disponível em: www.coi.columbia.edu/pdf/ stark_vedres_stns.pdf. Acesso em: 26 jan. 2013.

STUART, Taby; HOANG, Ha; HYBELS, Ralph. Interorganizationa endorsements and the performance of entrepreneurial ventures. Administrative science quarterly, v. 44, n. 2, p. 315-349, jun., 1999.

; SORENSON, Olav. Liquidity events and the geographic distribution of entrepreneurial activity. Administrative science quarterly, v. 48, n. 2, p. 175-201, jun., 2003.

THOMPSON, James. Organizations in action: social science bases of administrative theory. New York: McGraw-Hill, 1967

TRIGILIA, Carlo. Economic sociology: state, market, and society in modern capitalism. Oxford: Blackwell, 2002.

UZZI, Brin. The sources and consequences of embeddedness for the economic performance of organizations: the network effect. American sociological review, v. 61, n. 4, p. 674-698, ago., 1996. Disponível em: http://depts.washington.edu/ methods/readings/uzzi.pdf. Acesso em: 26 jan. 2013.

Social structure and competition in interûrm networks: the paradox of embeddedness. Administrative science quarterly, v. 42, n. 1, p. 35-67, mar., 1997.

LANCASTER, Ryan. Embeddedness and price formation in the corporate law market. American sociological review, v. 69, p. 319-344, jun., 2004. Disponível em: http:/ / www.kellogg.northwestern.edu/faculty/uzzi/ftp/ Embeddedness\%2520and\%2520Price\%2520Formation.pdf. Acesso em: 28 jan. 2013.

WADE, Robert. Governing the market: economic theory and the role of government in east Asian industrialization. Princeton: Princeton University Press, 1990.

WESTPHAL, James; ZAJAC, Edward. The symbolic management of stockholders: corporate governance reforms and shareholder reactions. Administrative science quarterly, v. 43, n. 1, p. 127-153, mar.,1998.
WHITE, Harrison. Chains of opportunity: system models of mobility in organizations. Cambridge: Harvard University Press, 1970.

Where do markets come from? American journal of sociology, v. 87, n. 3, p. 517-547, nov., 1981.

Markets from networks: socioeconomic models of production. Princeton: Princeton University Press, 2002.

WILLIAMSON, Oliver. The economic institutions of capitalism: firms, markets, relational contracting. New York: Free Press, 1985.Disponível em: www.sp.uconn.edu/ 〜langlois/Williamson\%20(1985),\%20chapter\%201.pdf. Acesso em: 26 jan. 2013.

YAMIGUSHI, Toshio; COOK, Karen. Generalized exchanges and social dilemmas. Social psychology quarterly, v. 56, n. 4, p. 235-248, dez., 1993

ZELIZER, Viviana. Morals and markets: the development of life insurance in the united states. New Brunswick: Transaction Books, 1983.

Pricing the priceless child: the changing social value of children. Princeton: Princeton University Press, 1994.

The social meaning of money. New York: Basic $\overline{\text { Books, }} 1997$.

Culture and consumption. In: SMELSER, Neil; SWEDBERG, Richard (Org.). The handbook of economic sociology. 2. ed. New York: Princeton University Press, 2005. p. 331-355

ZORN, Dirk. Here a chief, there a chief: the rise of the CFO in the American ûrm. American sociological review, Princiton, v. 69, p. 345-364, jun., 2004.

ZUCKERMAN, Ezra. The categorical imperative: securities analysts and the illegitimacy discount. American journal of sociology, Chicago, v. 104, n. 5, p. 1398-1438, mar., 1999.

Focusing the corporate product: securities analysts and dediversiûcation. Administrative science quarterly, $\mathrm{v}$. 45, n. 3, p. 591-619, set., 2000.

ZUKIN, Sharon; MAGUIRE, Jennife. Consumers and consumption. Annual review of sociology, v. 30, p. 173-198, 2004. 


\section{THE SOCIOLOGY OF MARKETS}

\section{Neil Fligstein \\ Luke Dauter}

Market Sociology has been one of the most vibrant fields in Sociology in the past 25 years. There is a great deal of agreement that markets are social structures characterized by extensive social relationships between firms, workers, suppliers, customers and governments. But, like in many sociological literatures, the theory camps that have formed often seem to speak by each other. We show that some of the disagreement between the theory camps is due to differences in conceptual language, and other disagreements stem from the fact that theory camps ignore the concepts in other theory camps, thereby making their theories less complete. We end by considering deeper controversies in the literature that seem open both to new conceptualization and to further empirical research.

KEY wORDS: fields, networks, institutions, performativity, culture, politics.

\section{LA SOCIOLOGIE DES MARCHÉS}

\author{
Neil Fligstein \\ Luke Dauter
}

La Sociologie des Marchés a été l'un des domaines les plus dynamiques de la Sociologie au cours des 25 dernières années. Il existe un assez large consensus considérant les marchés comme des structures sociales caractérisées par de vastes relations sociales entre les entreprises, les travailleurs, les fournisseurs, les clients et les gouvernements. Cependant, comme c'est le cas pour de nombreuses références sociologiques, les nouveaux champs théoriques semblent souvent s'affirmer sans prendre en considération les autres champs. Nous démontrons que certains désaccords entre les différents champs théoriques sont dus en partie au langage conceptuel mais aussi au fait que ces champs théoriques ne tiennent pas compte des concepts des autres domaines, ce qui fait que leurs théories restent incomplètes. Finalement nous analysons des controverses plus profondes dans des études réalisées qui sembleraient plus ouvertes autant à de nouvelles conceptualisations qu'à une recherche empirique complémentaire.

Mots-ClÉs: champs, réseaux, institutions, performativité, culture, politique.

Neil Fligstein - Professor do Departamento de Sociologia e Diretor do Centro para Cultura, Organização e Política/Instituto de Pesquisa em Trabalho e Emprego, na Universidade da Califórnia, Berkeley. Suas áreas de interesse são Sociologia Econômica, Teoria Organizacional, Sociologia Política e Sociologia do Trabalho. Suas publicações mais recentes incluem os livros A theory of fields (Oxford University Press, 2012, em coautoria com Doug McAdam), Euroclash: The EU, European identity, and the future of Europe (Oxford University Press, 2008) e The architecture of markets: an economic sociology of of capitalist societies (Princeton University Press, 2001), além de diversos artigos e capítulos de livro sobre temas como a relação entre mercado e política, teoria dos campos, habilidades sociais, as repercussões da crise financeira nos Estados Unidos e a construção de um mercado comum na integração europeia.

Luke Dauter - Candidato ao doutorado em Sociologia na Universidade da Califórnia, Berkeley. Seu programa de pesquisa está relacionado às mudanças institucionais na educação pública norte-americana. Seu trabalho examina especificamente as condições para a heterogeneidade na dinâmica dos campos em contextos organizacionais locais. 